\title{
Framework to Manage Aging Oleochemical Plant Assets through Computerized Maintenance Management System
}

\author{
Tee Wooi Keat, Mohamad Wijayanuddin, Harisun Ya'akob \\ School of Chemical \& Energy Engineering, Universiti Teknologi Malaysia, Skudai, Johor, Malaysia \\ Email: wooikeat.tee@gmail.com,mwali@utm.my, harisun@ibd.utm.my
}

How to cite this paper: Keat, T. W., Wijayanuddin, M., \& Ya'akob, H. (2021). Framework to Manage Aging Oleochemical Plant Assets through Computerized Maintenance Management System. American Journal of Industrial and Business Management, 11, 611-620.

https://doi.org/10.4236/ajibm.2021.116039

Received: May 9, 2021

Accepted: June 4, 2021

Published: June 7, 2021

Copyright () 2021 by author(s) and Scientific Research Publishing Inc.

This work is licensed under the Creative Commons Attribution International License (CC BY-NC 4.0).

http://creativecommons.org/licenses/by-nc/4.0/

\begin{abstract}
The aim of this study is to provide insights and promotes awareness and understanding of related aging factors in oleochemical industry. Establish a framework to manage aging assets through computerized maintenance management system (CMMS). The methodology adopted was to identify key factors related to aging failure based on collation of incidents and breakdowns from one of the largest oleochemical industries in Malaysia. The databases of incident reports and breakdown were reviewed in detail and make judgment on whether or not any of them was a contributing factor to aging failure. The framework in aging asset management was developed based on multiple successful CMMS implementation and roll outs, suitable to be implemented in any CMMS software. The findings of data and reviews are incorporated into the framework to manage and maintain the service life of each aging assets in oleochemical industry effectively. The framework also helps and guides maintenance managers, engineers and practitioners understand aging factor, deal pragmatically with safety, environmental and business risk to meet statutory and company requirements. This research has shown that aging related failure M.O.D.E (maintenance, operation, design and environment) are significant contributor to aging related incident or breakdown in oleochemical industry. These aging assets can be managed effectively through guided and systematic framework in CMMS to address the aging related failure across all relevant asset types as available in oleochemical industry.
\end{abstract}

\section{Keywords}

Aging, Asset, CMMS, Framework, Oleochemical

\section{Introduction}

The oleochemical industry in Malaysia started in the early 1980s. The industry 
expanded rapidly and today it is one of the largest oleochemical industries of the global capacity. To ensure the industry stays competitive with reliable operation and maximize the return of the capital investment, it is prudent for all assets to perform their design intended function throughout its service life in a safe, effective and efficient manner. This can only be achieved through an established asset management system and leverage of the new advancement in technology and CMMS to support the above function.

Most oleochemical plants in Malaysia are aging, this severely affects the competitiveness of the industry by reducing throughput due to unplanned outages, leading to loss of yield and competitive advantage. A similar asset management program in enhancing reliability and maintainability is commonly applied in the oil and gas, petrochemical industry as an important function in ensuring that a production facility continues to produce optimally through their plants and equipment. One of the major challenges in the oleochemical industry is to manage sophisticated, equivalent complexities of plant aging assets with deficient asset management and maintenance systems.

With the rapid advancement of digitalization and technology, e-maintenance such as computerized maintenance management (CMMS) is key to improve asset management, especially to manage and maintain the enormous number of production assets. To support maintenance function, CMMS enables each organization to plan, track, measure, and collect information continuously on each asset. This enables an organization in making a smarter and data-based decision. However, there is no specific standard or framework in guiding the management of aging assets through CMMS which defines the need of this research.

\section{Review}

\subsection{Asset Management in Industry}

Following the emerging trend in asset reliability management, ISO 5000 series that standardized guidelines in managing assets were developed. The ISO 55000 asset management standard offers numerous tangible and intangible benefits to asset-intensive organizations but implementing a successful compliant can be a daunting task. Over the past decade, the collaborative effort of hundreds of participants, across multiple industries from 28 counters has identified universal best practices for asset management. Published by the International Organization for Standards, ISO 5000, 55001, and 55002 deliver a disciplined framework, incorporating a comprehensive, risk-based approach. This holistic integrated framework ensures a balance between risk, cost, and performance for the lifecycle of assets guides for doing "the right work, on the right asset, at the right time."

\subsection{Importance of Asset Management}

The term "asset management" first came to light in the mid-to-late 1960s (Builta, 1994) and the study in asset management started to surface in the fields of 
the transport system, public infrastructure, public health systems, etc. (Vanier, 2001). In manufacturing, maintenance cost is a major part of the total operating costs of manufacturing and production plants as it represents from 15 to 40 percent of the cost of produced goods (Widodo \& Yang, 2011). Competition on a global scale, fast-changing customer needs, shorter product life cycles demand a high level of efficiency in all industrial environments (Groger et al., 2012). Along the way, the petroleum industry adapted to the emergence of asset management practice and it has become an important part of the industry. The reason is petroleum's either onshore or offshore assets are known to be high risk, thus strategically managing the assets is highly important as a way to be sustainable $(\mathrm{Ku}-$ sumawardhani, Kumar, \& Tore, 2016). Defining the best maintenance strategy represents a critical issue for all kind of production industries. Through emerging internet of things and technology, data driven maintenance strategy is developed and applied to most oil refinery plants. Maintenance is deemed as a focal point in the production process of refinery plants to ensure reliable operation (Antomarioni, Bevilacqua, Potena, \& Diamantini, 2019).

\subsection{Challenges in Asset Management}

Asset management is often misunderstood by organizations as a mere financial burden. Inspection and maintenance of plant and machinery have traditionally been based on prescriptive industry practices (Tsang, 2002). There are other identified challenges such as insufficient resources, suppliers, and training support (Luxhoj et al., 1997), technical challenges such as aging equipment, corrosion, degradation and cracking (Al-Sulaiman et al. 2013), human-induced error challenges (Skalle et al., 2014), as well as challenges in engineering design (Ghani et al., 2014). Organizations have expressed their challenges in implement asset reliability management and the major concerns were regarding managerial decisions, human resources, cost, and degradation. Some of the challenges can be related to operation reliability such as inadequate work procedures, record keeping, safety culture, training and, competency, etc. It is important to raise awareness of the importance of asset management (Kusumawardhani, Kumar, \& Tore, 2016).

\subsection{Computerized Maintenance Management System (CMMS)}

Before the existence of a computerized maintenance management system (CMMS), obtaining centralized, dynamic visibility and automated management was impractical because maintenance information was buried in paper files and later scattered across spreadsheets. These computer-based software programs used to control work activities and resources used, as well as to monitor and report work execution. CMMS also served as a tool for data capture and analysis. It provides management with value-added information necessary for maintenance decision making (Fernandez, Labib, Walmsley, \& Petty, 2003). According to IBM, the 2000s saw the emergence of intranets and web-based connectivity that expanded CMMS capabilities to a range of mobile devices, field applications, and opera- 
tional sites. The latest generation of CMMS is cloud-based and highly mobile. Computerization is essential to a successful framework development endeavor.

The core of a CMMS is its database and data model that organizes information about the assets an organization is managing or maintaining, as well as the equipment details, materials, and other resources to do so. With continuous data build-up, the benefits of having an individualized maintenance framework will become apparent (Daragh, Naughton, \& Tiernan, 2012). As the number of data sources available to the asset continues to grow, managing, merging, and analyzing these pools of data at speed will be a tremendous challenge for each organization without a proper CMMS or framework in managing these assets put asides some organizations have yet to move past legacy systems and spreadsheet for critical asset functions like maintenance plan, work schedule, and execution management.

\section{Key Factors Contributed to Aging Failure (M.O.D.E) in Oleochemical Industry}

Published data of relative key factors related to aging failure is scarce. From the incidents and breakdown records in one of the largest oleochemical plants in Malaysia, it recorded the total numbers of aging failures from all assets of different object types and ages over three years, from 2018 to 2020. The bar charts in Figure 1 show the contribution of aging failures which can be categorized under four key factors i.e., maintenance, operation, design, and environment.

However, this study mainly focuses on maintenance as one of the core factors that led to aging failure. It is intended as part of this study to provide a framework to manage aging asset through CMMS. This study does not include other factors such as operation, environment, and design which will be partially addressed through the framework, international standards and future study.

\subsection{Maintenance}

Maintenance-related issues were identified as one of the core factors contributing to aging failure. It is important to recognize that many systems and features

\section{Key Factors Related to Aging Failure (M.O.D.E)}

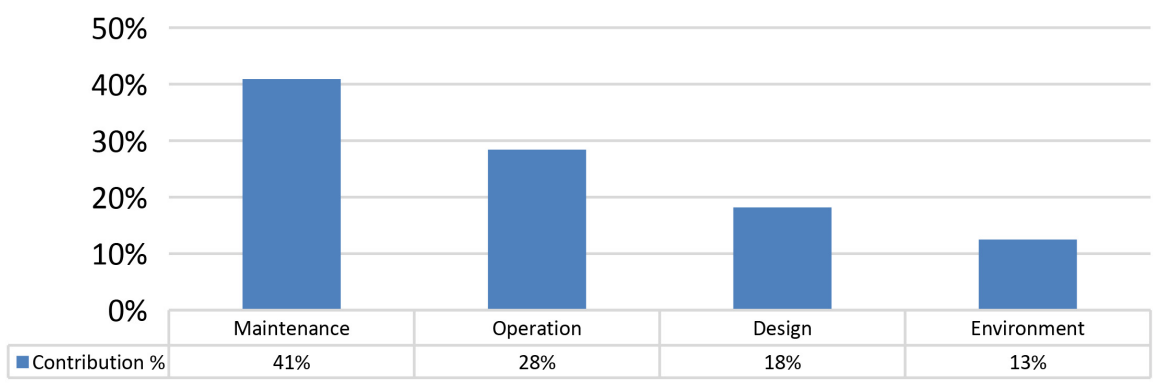

Figure 1. Key factors contributed to aging failure (M.O.D.E). Source: Actual breakdowns and incidents data from one of the largest oleochemical plant in Malaysia (2018-2020). 
which subject to aging can compromise the health, safety, and environment performance of the plant. Good maintenance management processes and practices are central to ensuring that aging assets continue to operate safely and reliably. Maintenance workflow as covered in EN 13460 as shown in Figure 2 specified a set of sequenced steps to be followed to accomplish a maintenance operation can be further improved with full integration to CMMS module as well as international standards in managing aging assets.

\subsection{Maintenance Framework}

The Global Forum on Maintenance and Asset Management (GFMAM) produces a framework as shown in Figure 3 intended to be used by the maintenance and asset management communities. It shows generally how the maintenance management subject groups fit with each other and to the objectives of the organizational business plan. Besides that, they recognized there is no one common workflow for maintenance management. The workflow depends uniquely on the organization and its environment (GFMAM, 2014).

\section{Aging Asset (Equipment) and Management}

Research report 509 defined aging and aging equipment as "aging is not about how old an equipment is, it is about its condition, and how that is changing over time. All types of equipment can be susceptible to aging mechanisms. The significance of deterioration and damage related to potential effect on equipment's functionality, availability, reliability, and safety." The issue of aging plant leading to an increased risk of containment and other failures due to plant and equipment deterioration demonstrates the significant extent and impact of aging plant-related failures on safety, environmental, and business performance.

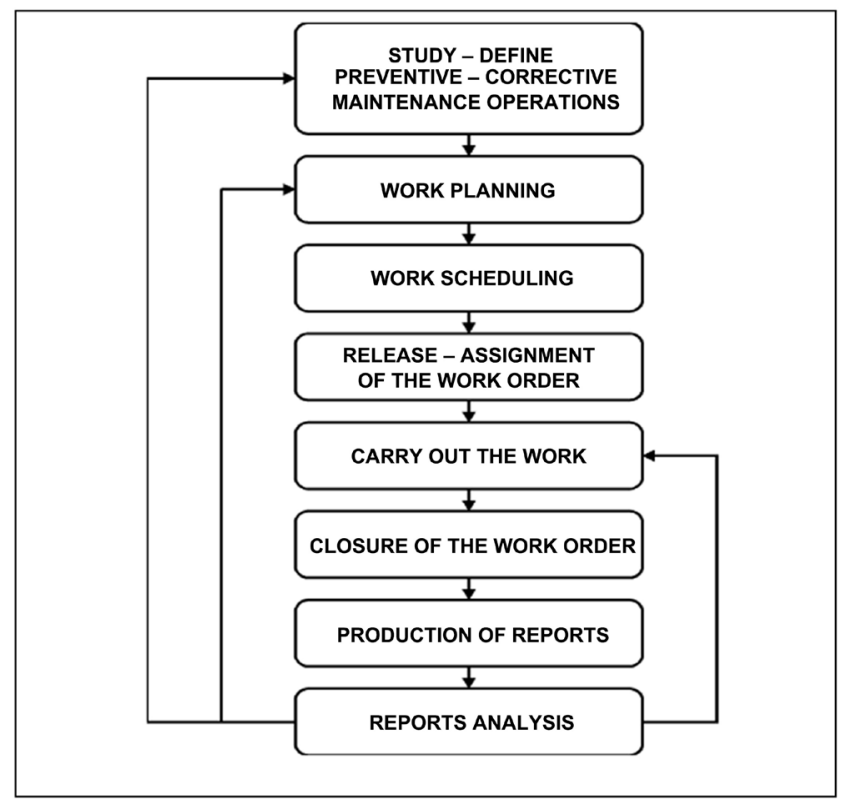

Figure 2. The maintenance workflow. 


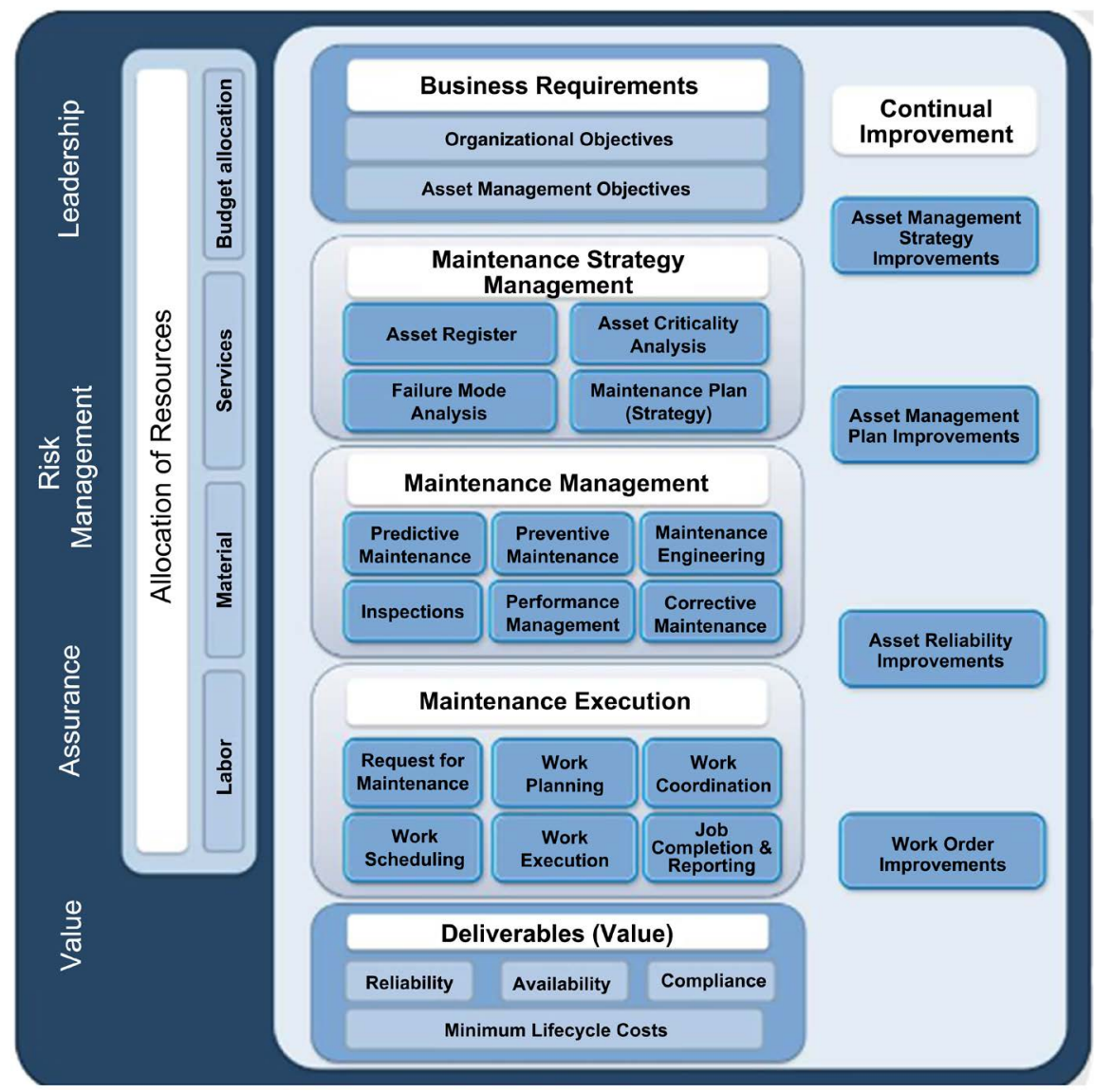

Figure 3. The maintenance management framework (GFMAM, 2014).

At the same time, research report 823 serves as a guide in providing a useful resource for industry, both in terms of understanding health, safety, and environmental approach, understanding the issues and expectations on industry for managing aging assets, and in raising awareness throughout industry of the effects of aging plant and how this can be managed effectively.

\subsection{Conceptual Framework to Manage Assets through Computerized Maintenance Management System}

Successful implementation of a computerized maintenance management system (CMMS) requires a strategic framework to get the most value out of the system (Tee, Wijayanuddin, \& Harisun, 2019).

A conceptual strategic asset management maintenance framework is developed from multiple successful CMMS roll-outs and implementation in the oleochemical industry (Tee, Wijayanuddin, \& Harisun, 2020). Each stage as depicted in Figure 4 below is suitable to be applied in any CMMS software and module.

This framework is proven to be user-friendly and guided maintenance practitioners in upkeeping plant assets with continuous review and improvement in terms of assets condition as well as maintenance strategies to ensure all assets are accountable, operate safely and reliably. 


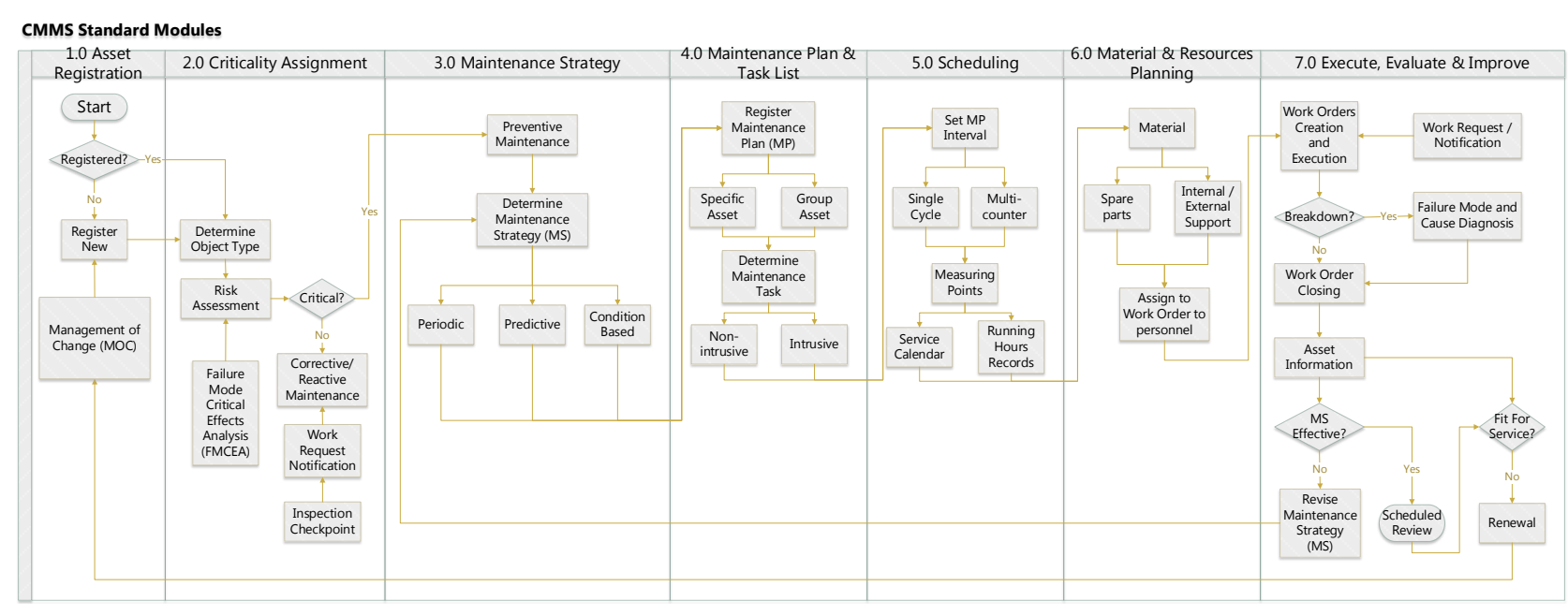

Figure 4. Conceptual strategic asset maintenance management framework, adopted from (Tee, Wijayanuddin, \& Harisun, 2020).

\subsection{Framework to Manage Aging Assets through Computerized Maintenance Management System}

The above conceptual framework was then further expanded to manage aging oleochemical plant assets through CMMS in accordance with international standards. A new framework provides a guideline on how to plan, perform, record, and maintain an aging asset by providing the steps in accordance with International Standards and examples in applications.

\subsection{Framework in Accordance with International Standards}

This new framework provides an overview of aging asset management through a computerized management system (CMMS). In the preparation of this framework, the study has identified a common framework and workflow that can be applied to the broadest range of aging assets. This framework can be used in combination with any relevant sector, asset types, and technical specifications. The adoption of this new framework following International Standards as shown in Table 1 and Table 2 complements and assures maintainability, operability, and safety of aging assets can be achieved consistently and sustainably over their lifecycle.

Till now, there is no standard framework to guide maintenance practitioners to manage assets through CMMS in a structural manner. Most implementation is mainly based on the CMMS consultants or subject matter experts which highly depends on the organization's resources in supporting this initiative and full-scale roll-out. This can be a complicated and costly exercise. With scarce resources, this framework serves as a general guideline to put an end to time-consuming, unclear, and ineffective CMMS implementation but to empower the team to design and prioritize asset management in particular aging type of assets which require attention to mitigate the risk of any major hazard accidents.

\subsection{Application with Standard Computerized Maintenance Management System (CMMS)}

This framework was validated in few well-known computerized maintenance 
management systems (CMMS) and it fits well into these systems. It was summarized in Table 3 to confirm the availability of respective steps and suitability of the application framework under relevant CMMS modules.

Table 1. Summary of the framework in accordance with relevant international standards.

\begin{tabular}{|c|c|c|c|c|c|c|c|c|c|c|}
\hline \multirow[b]{2}{*}{ Step } & \multicolumn{10}{|c|}{ International Standards } \\
\hline & PAS55-1, 2 & $\begin{array}{l}\text { ISO } \\
5500 \mathrm{x}\end{array}$ & $\begin{array}{c}\text { EN } \\
13306\end{array}$ & $\begin{array}{c}\text { EN } \\
13460\end{array}$ & $\begin{array}{c}\text { EN } \\
60300-3-11\end{array}$ & $\begin{array}{c}\text { EN } \\
16646\end{array}$ & $\begin{array}{c}\text { EN IEC } \\
60812\end{array}$ & EN 15341 & RR509 & RR823 \\
\hline Asset Creation and Registration & A & & & & & A & A & & & \\
\hline Criticality assignment & A & & & & A & & & & A & A \\
\hline Maintenance strategy & A & A & A & A & A & A & A & & A & A \\
\hline Maintenance plan and task list & A & A & & A & A & A & A & & A & A \\
\hline Scheduling & & & & A & A & & & & & \\
\hline Material and resources planning & & A & & & A & & & & A & \\
\hline Execute, evaluate, and enhance & A & A & & A & A & A & & A & A & A \\
\hline
\end{tabular}

"A" refers to applicable standard.

Table 2. Reference international standards code.

\begin{tabular}{|c|c|}
\hline \multirow{2}{*}{ Reference Code- } & Standard Reference \\
\hline & Title \\
\hline \multirow{3}{*}{ PAS55-1, 2} & Asset management \\
\hline & Part $1-$ specification for the optimized management of physical assets \\
\hline & Part 2-guidelines for the application of PAS 55-1 \\
\hline \multirow{4}{*}{ ISO $5500 \mathrm{X}$} & Asset management \\
\hline & ISO 55000-overview, principle, and terminology \\
\hline & ISO $55001-$ management system, requirements \\
\hline & ISO 55002-management system, guidelines for the application of ISO 55001 \\
\hline EN 13306 & Maintenance terminology \\
\hline EN 13460 & Documents for maintenance \\
\hline EN 60300-3-11 & Application guide - reliability centered maintenance (RCM) \\
\hline EN 16646 & Maintenance within physical asset management \\
\hline EN IEC 60812 & Failure modes and effect criticality analysis (FMEA and FMECA) \\
\hline EN 15341 & Maintenance key performance indicators \\
\hline RR 509 & Plant aging-management of equipment containing hazardous fluids or pressure \\
\hline RR 803 & Managing aging plant-a summary guide \\
\hline
\end{tabular}

Table 3. Summary of the application framework in accordance with relevant CMMS.

\begin{tabular}{cccccc}
\hline \multirow{2}{*}{ Step } & \multicolumn{4}{c}{ Computerized maintenance management system (CMMS) } \\
\cline { 2 - 6 } & SAP PM & IBM MAXIMO & Fiix & MEX & CWorks \\
\hline Country of Origin & Germany & USA & Canada & Australia & Malaysia \\
Asset Creation and Registration & A & A & A & A & A \\
\hline
\end{tabular}




\section{Continued}

\begin{tabular}{cccccc}
\hline $\begin{array}{c}\text { Criticality assignment } \\
\text { Maintenance strategy }\end{array}$ & A & A & A & A & A \\
Maintenance plan and task list & A & A & A & A & A \\
Scheduling & A & A & A & A & A \\
Material and resources planning & A & A & A & A & A \\
Execute, evaluate, and enhance & A & A & A & A & A \\
\hline
\end{tabular}

"A" refers to the availability of respective steps in the CMMS module.

\section{Conclusion and Recommendation}

The research offers a framework to help and guide maintenance managers, practitioners, and non-specialist engineers to manage aging assets systematically through a computerized maintenance management system in compliance with International Standards. It also provides insights and promotes awareness, understanding of related aging factors in the oleochemical industry. This structural approach will enable aging plants to continue to operate their assets safely and reliably under more demanding conditions with extended service life.

However, still many important research questions and technical input needs remain such as maintenance strategy selection to further develop, improve, and perfecting this framework. There is also a need for empirical research in the future to validate the multifaced perspective in the present research and to gain more insight in aging asset management related to other key factors such as operational, design, and environment. This will help to derive a suitable framework to address different aging factors for all other organizations with different kinds of assets onset of aging.

\section{Acknowledgements}

We are grateful to all those with whom we have had the pleasure to work with during this research. Each of the members has provided us extensive personal and professional input in completing this research.

\section{Conflicts of Interest}

The authors declare no conflicts of interest regarding the publication of this paper.

\section{References}

Al-Sulaiman, S., Sardesai, V., Murthy, H.S., Reddy, N.H., \& John, R.P. (2013). Asset Integrity Challenges in Oil \& Gas Process Facilities. Paper Presented at International Petroleum Technology Conference, Beijing, 26 March 2013, Paper No. IPTC-16646-MS. https://doi.org/10.2523/IPTC-16646-MS

Antomarioni, S., Bevilacqua, M., Potena, D., \& Diamantini, C. (2019). Defining a Data-Driven Maintenance Policy: An Application to an Oil Refinery Plant. International Journal of Quality \& Reliability Management, 36, 77-97. 
https://doi.org/10.1108/IJQRM-01-2018-0012

Builta, H. C. (1994). Asset Management. In M. Arnold (Ed.), Fundamentals of Real Property Administration (pp. 83-100). Arnold, MD: Building Owners and Managers Institute International, Inc.

Daragh Naughton, M., \& Tiernan, P. (2012). Individualizing Maintenance Management: A Proposed Framework and Case Study. Journal of Quality in Maintenance Engineering, 18, 267-281. https://doi.org/10.1108/13552511211265802

Fernandez, O., Labib, A. W., Walmsley, R., \& Petty, D. J. (2003). A Decision Support Maintenance Management System. International Journal of Quality \& Reliability Management, 20, 965-979. https://doi.org/10.1108/02656710310493652

Ghani, O., Kamaruzaman, M., Sulaima, M. F., \& Othman, M. N. (2014). An Engineering Ethics Case Study Review: Petrobras P-36 Accident. International Journal of Engineering and Science, 3, 46-50.

Global Forum on Maintenance and Asset Management (GFMAM) (2014). The Asset Management Landscape (2nd ed.). https://www.gfmam.org

Gröger, C., Niederma, F., \& Mitschang, B. (Eds) (2012). The 2012 International Conference of Manufacturing Engineering and Engineering Management. In: The 2012 International Conference of Mechanical Engineering, World Congress on Engineering (1475-1481). Hong Kong, London: International Association of Engineers.

Kusumawardhani, M., Kumar, R., \& Tore, M. (2016). Asset Integrity Management: Offshore Installations Challenges. Journal of Quality in Maintenance Engineering, 22, 238-251. https://doi.org/10.1108/JQME-06-2015-0023

Luxhoj, J. T., Riis, J. O., \& Thorsteinsson, U. (1997). Trends and Perspectives in Industrial Maintenance Management. Journal of Manufacturing Systems, 16, 437-453. https://doi.org/10.1016/S0278-6125(97)81701-3

Skalle, P., Aamodt, A., \& Laumann, K. (2014). Integrating Human Related Errors with Technical Errors to Determine Causes behind Offshore Accidents. Safety Science, 63, 179-190. https://doi.org/10.1016/j.ssci.2013.11.009 http://www.sciencedirect.com/science/article/pii/S0925753513002671

Tee, W. K., Wijayanuddin, M., \& Harisun, Y. (2019). Strategic Asset Management Maintenance Framework in Asset Reliability Management for Oleochemical Industry in Malaysia. Advanced Journal of Technical and Vocational Education (AGTVE) Journal, 3, 7-13.

Tee, W. K., Wijayanuddin, M., \& Harisun, Y. (2020). Implementation of Computerized Maintenance Management System Based on Conceptual Strategic Asset Management Maintenance Framework for Oleochemical. Test Engineering and Management, 83, 9907-9912.

Tsang, A. H. C. (2002). Strategic Dimensions of Maintenance Management. Journal of Quality in Maintenance Engineering, 8, 7-39. https://doi.org/10.1108/13552510210420577

Vanier, D. (2001). Why Industry Needs Asset Management Tools. Journal of Computing in Civil Engineering, 15, 35-43. https://doi.org/10.1061/(ASCE)0887-3801(2001)15:1(35)

Widodo, A., \& Yang, B. S. (2011). Application of Relevance Vector Machine and Survival Probability to Machine Degradation Assessment. Expect Systems with Application: An International Journal, 38, 2592-2599. https://doi.org/10.1016/j.eswa.2010.08.049 